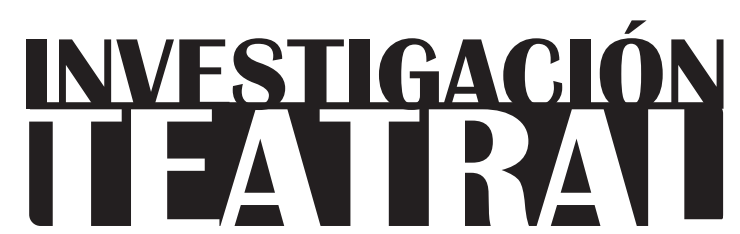

Revista de artes escénicas y performatividad

Vol. 12, Núm. 19

abril-septiembre 2021

Segunda época

ISSN impreso: $1665-8728$

ISSN electrónico: 2594-0953

Universidad Veracruzana
Reseña de puesta en escena

I wonder where the dreams I don't remember go, de Yoann Bourgeois

\author{
Yaeko Ramírez Tovar*
}

Recibido: 07 de diciembre de 2020

Aceptado: 09 de febrero de 2021

Doi: $10.25009 /$ it.v12i19.2668 


\section{I wonder where the dreams I don't remember go, de Yoann Bourgeois} coreografía I wonder where the dreams I don't remember go, bajo la dirección del coreógrafo francés Yoann Bourgeois, una coreografía marcada por el estilo característico de Bourgeois, donde el desafío a la gravedad es el eje principal. Nederlands Dans Theater es una compañía de danza originaria de los Países Bajos y una de las pocas en el mundo que invita a diferentes coreógrafos anualmente, brindándoles la oportunidad de crear nuevas obras con una virtuosa y preparada compañía. Fue fundada por Benjamin Harkarvy, Aart Verstegen y Carel Birnie, en 1959. Su repertorio se conforma por 620 obras de reconocidos coreógrafos y coreógrafas, como Jiří Kylián y Hans van Manen, Sol León y Paul Lightfoot, Crystal Pite y Marco Goecke, Johan Inger, Medhi Walerski, Ohad Naharin, Alexander Ekman, Gabriela Carrizo, Franck Chartier, Hofesh Shechter, Edward Clug, Sharon Eyal, Gai Behar y muchos más. Actualmente, Nederlands Dans Theater tiene, como directora artística, a Emily Molnar ${ }^{1}$ y, como directora general, a Willemijn Maas. Se conforma por los grupos NDT1 y NDT2. El primero está integrado por jóvenes profesionales y talentosos; el segundo, por bailarines con una trayectoria más larga.

Para su temporada 2020-2021, debido a la epidemia de COVID-19, la compañía ofrece dos alternativas: funciones presenciales en Lucent Danstheater, en La Haya, Países Bajos, con público limitado, y funciones virtuales disponibles para todo el mundo, pagando un

1 Emily Molnar es una de las más aclamadas bailarinas de Canadá. Es egresada de la National Ballet School of Canada y bailó con la National Ballet of Canada, Ballet BC y el Frankfurt Ballet. 
boleto. Gracias a esta segunda alternativa, miles de espectadores nos dimos cita en su página web para presenciar, desde la comodidad de nuestros hogares, el estreno de I wonder where the dreams I don't remember go. Yoann Bourgeois ${ }^{2}$ es un acróbata, actor, malabarista, bailarín y coreógrafo originario de Francia. Sus obras se caracterizan por la fascinación que tiene con la gravedad y por las instalaciones que utiliza, donde muy frecuentemente desafía las fuerzas de la física. Su primera coreografía con el grupo 2 de Nederlands Dans Theater fue durante la temporada 2019-2020; se tituló Little Song.

I wonder where the dreams I don't remember go es una "exploración poética del tiempo, espacio y las fuerzas físicas"3 ("I wonder" 2) que "propicia nuestra imaginación en un nuevo e inesperado territorio, ofreciéndonos un convincente universo que cuestiona nuestro sentido de realidad"4 (ibidem).

La primera imagen que se observa en la coreografía es uno de los intérpretes parado frente a la cámara. Invita a presenciar la función y señala que lo que está a punto de suceder es un poema. Una vez que se abre el telón, al fondo se observa una estructura de madera, conformada por dos paredes continuas y un piso. Hay una mesa con dos sillas y, en una de ellas, está una mujer. El intérprete se sienta con ella. Sentados en la mesa mantienen un corto diálogo, ninguno sabe con exactitud dónde están. Pareciera que el espacio que ambos habitan no es el mismo (ver Imagen 1). La mujer se pone de pie, toma su silla y la embona a una de las paredes de la estructura de madera. La silla queda en posición horizontal, como si estuviera suspendida.

Tanto la mesa como las sillas, así como el uso de estructuras que permitan la interacción de los intérpretes con estas, son elementos sumamente recurrentes en las obras de Bourgeois. En el caso de I wonder where the dreams I don't remember go, el coreógrafo lleva la exploración con estos elementos más allá de lo que ha hecho en otras obras.

La estructura de madera que está en el escenario es el elemento principal que convierte al espacio físico en un espacio onírico, donde las nociones de arriba y abajo no representan lo que en la vida cotidiana son (ver Imagen 2). Es una estructura que, conforme se transforma a lo largo de la coreografía, recuerda a Relatividad, la pintura de Maurits Cornelis Escher, donde justamente se aprecia la manera en que el pintor manipula el espacio y la perspectiva, experimentando con la gravedad y la construcción de espacios y arquitecturas imposibles.

Ver https://www.youtube.com/watch?v=Df7n-k2Cq34

3 "A poetic exploration of time, space and the physical forces".

4 "[...] propels our imagination into new and unexpected territory, offering us a compelling universe that questions our sense of reality". 
INVESTIGACIÓNTEATRAL

Revista de artes escénicas y performatividad

Vol. 12, Núm. 19

abril-septiembre 2021
I wonder where the dreams I don't remember go, de Yoann Bourgeois

Yaeko Ramírez Tovar
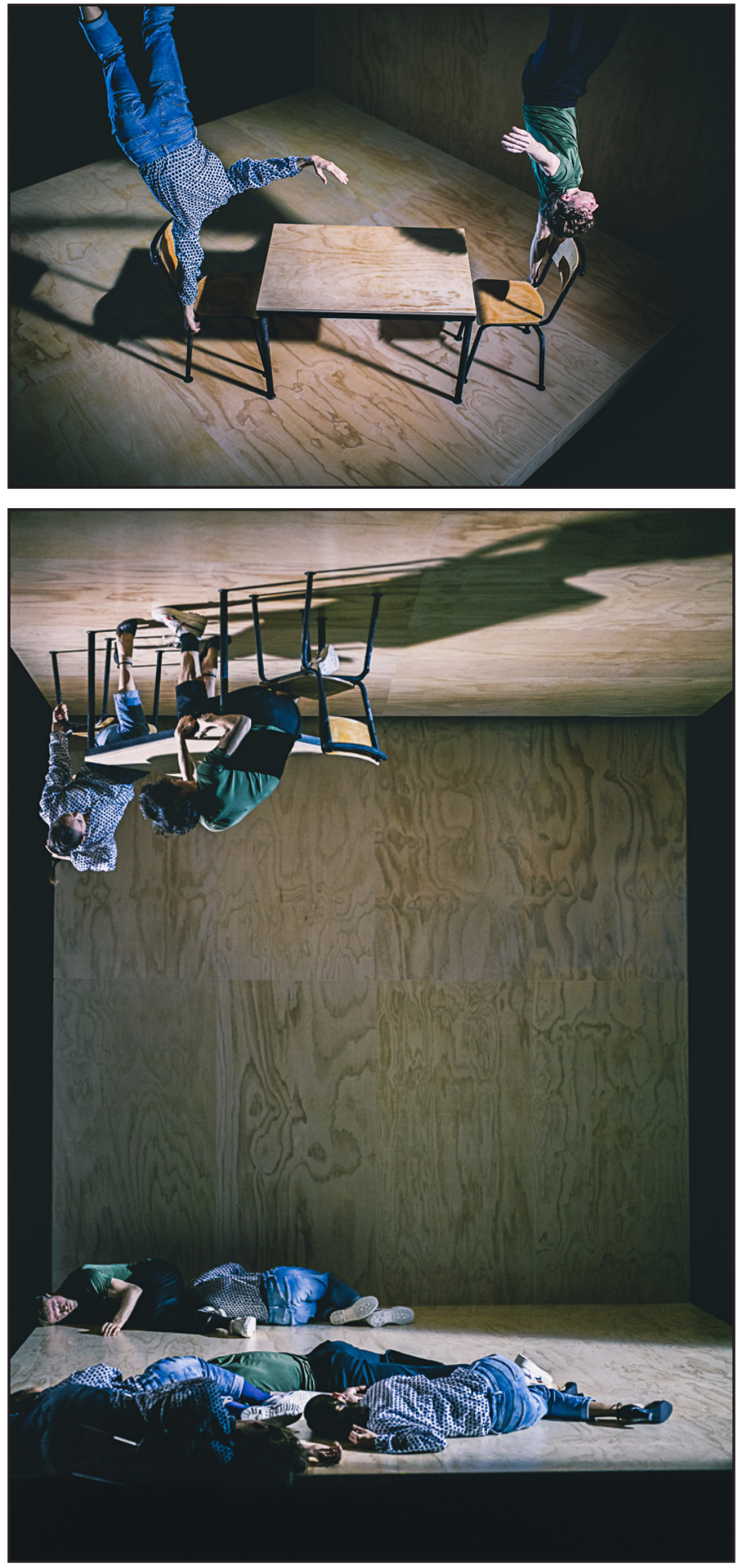

Imagen 1.@ Rahi Rezvani. Nederlands Dans Theatre, Yoann Bourgeois, I wonder where the dreams I don't remember go. Intérpretes: Surimu Fukushi, Nicole Ishimaru, Keren Leiman, Tess Voelker, Lea Ved, Scott Fowler, Boston Gallacher y Kyle Clarke. Lucent Danstheater, La Haya, Países Bajos, 2020.

Imagen 2.@ Rahi Rezvani. Nederlands Dans Theatre, Yoann Bourgeois, I wonder where the dreams I don't remember go. Intérpretes: Keren Leiman, Tess Voelker, Lea Ved, Scott Fowler, Nicole Ishimaru, Boston Gallacher y Kyle Clarke. Lucent Danstheater, La Haya, Países Bajos, 2020. 
Durante un primer momento, la coreografía transcurre en la creación del espacio onírico de la intérprete. ¿Cómo saber que es un sueño? Si por algo se caracterizan los sueños es por crear situaciones irreales que en ningún otro momento de la vida cotidiana podríamos presenciar ni hacer. Así es como el cuerpo de la intérprete se transforma en un cuerpo virtual que se proyecta en una de las paredes de la estructura de madera. Hay dos cuerpos de ella en el escenario y cada uno se distingue desde una perspectiva. La intérprete juega con la silla que sigue suspendida en la pared. Con movimientos sutiles y muy precisos hace que, tanto las imágenes de su cuerpo físico como de su cuerpo virtual, cobren vida en una secuencia de irrealidad e ilusión.

En un segundo momento de la coreografía, hay un flujo continuo de cuerpos físicos y virtuales en la estructura de madera. El efecto que se logra es como si los dos cuerpos que estaban en un inicio sentados en la mesa se hubieran multiplicado y cada uno imitara al otro. En escena se percibe caos. La tranquilidad y sutileza del inicio se interrumpe por voces intempestivas que hablan al mismo tiempo y se preguntan: “¿sabes dónde está mi pez dorado?".

Durante 40 minutos, en escena se mira una serie de sinsentidos: paredes que se mueven en distintos ángulos, sillas y mesas suspendidas, cuerpos que aparentemente son la misma persona, diálogos que se repiten y cuerpos escurriéndose por las paredes y deslizándose por el piso. En el desarrollo de la coreografía se crea un ambiente que no resulta fácil de definir (ver Imagen 3). Así como en los sueños, la coreografía muestra un tiempo diluido, donde cada segundo y cada minuto pierden relevancia entre el movimiento lúdico y los cuerpos. En este tiempo diluido, las voces que se escuchan y la música que acompañan al movimiento son fundamentales para irrumpir en lo onírico.

I wonder where the dreams I don't remember go es una coreografía de lo imposible, aunque también es un poema de lo onírico, donde cuerpos, almas, mentes, emociones y palabras se entremezclan con movimiento. La propuesta presentada por Nederlands Dans Theater y dirigida por Yoann Bourgeois es la muestra de un espacio onírico construido desde un proceso creativo en colectivo, donde cada uno de los y las intérpretes deposita un poco de su propia experiencia.

A pesar de que elementos como las sillas, la mesa o una rampa son recurrentes y representativos de otras obras de Bourgeois, en I wonder where the dreams I don't remember go son usados con mucha habilidad y naturalidad por los y las intérpretes. Pareciera lo más normal que una mesa esté completamente de cabeza y en ella dos personas sentadas en sillas haciendo movimientos perfectamente medidos para no caerse sobre el escenario.

La coreografía emana armonía entre el caos y peligro que se genera al desafiar la gravedad, así como lo efímero de los movimientos y los cuerpos proyectados en la estructura. La tensión que se produce por el constante peligro en el que están inmersos los y las 
INVESTIGACIÓNTEATRAL

Revista de artes escénicas y performatividad

Vol. 12, Núm. 19

abril-septiembre 2021
I wonder where the dreams I don't remember go, de Yoann Bourgeois

Yaeko Ramírez Tovar

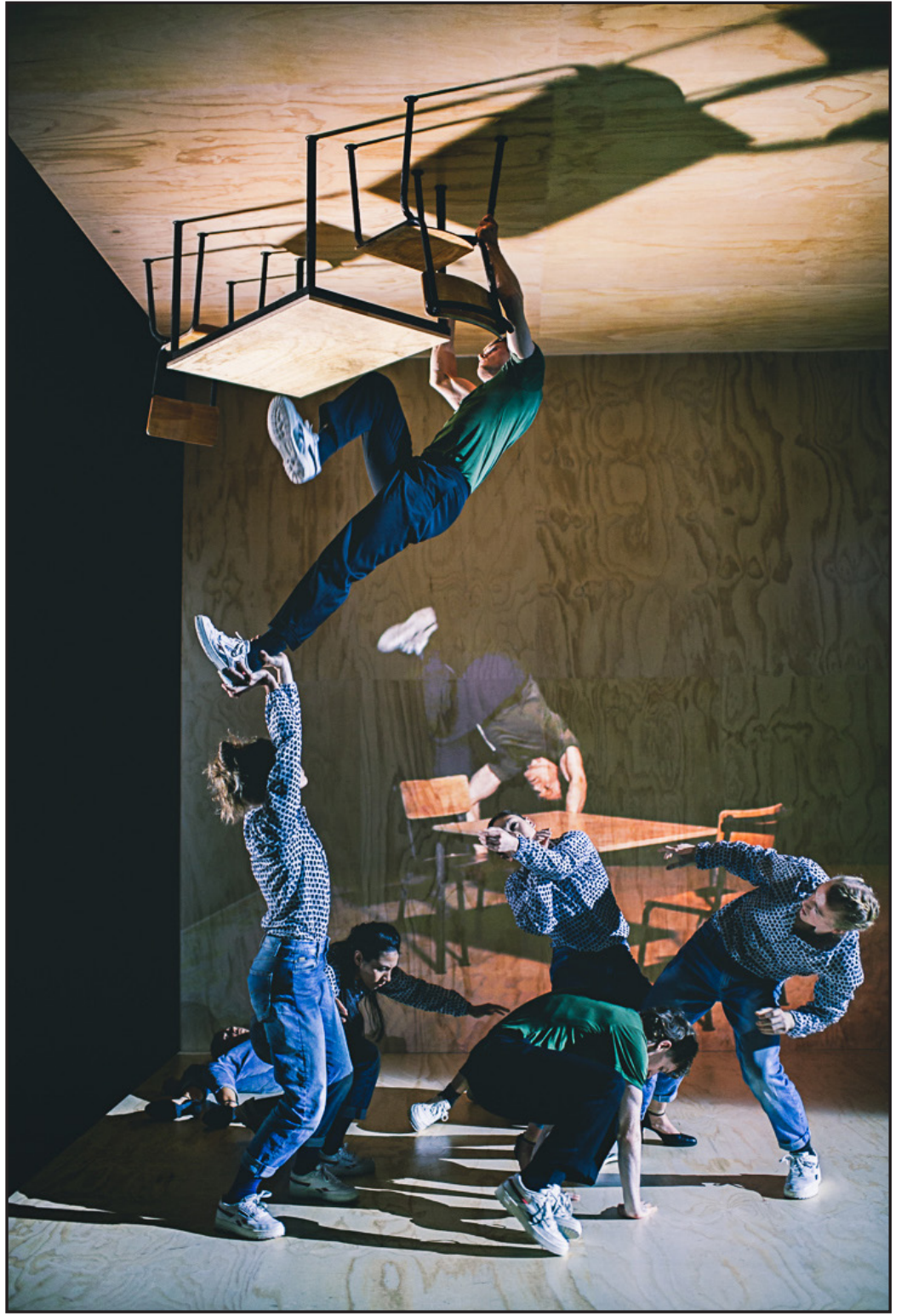

Imagen 3.๑ Rahi Rezvani. Nederlands Dans Theatre, Yoann Bourgeois, I wonder where the dreams I don't remember go. Intérpretes: Keren Leiman y Boston Gallacher. Lucent Danstheater, La Haya, Países Bajos, 2020.

intérpretes al estar de cabeza en el techo de la estructura sin ninguna protección, se rompe con las imágenes ilusorias e irreales que se perciben en el escenario. Incluso, hacen que se olvide el peligro que conlleva la misma coreografía (ver Imagen 4). Destaca notoriamente la destreza de los y las intérpretes para desarrollar secuencias de movimiento dentro de una estructura que asemeja un mundo al revés, un mundo de lo imposible. 
INVESTIGACIÓNTEATRAL

Revista de artes escénicas y performatividad

Vol. 12, Núm. 19

abril-septiembre 2021
I wonder where the dreams I don't remember go, de Yoann Bourgeois

Yaeko Ramírez Tovar

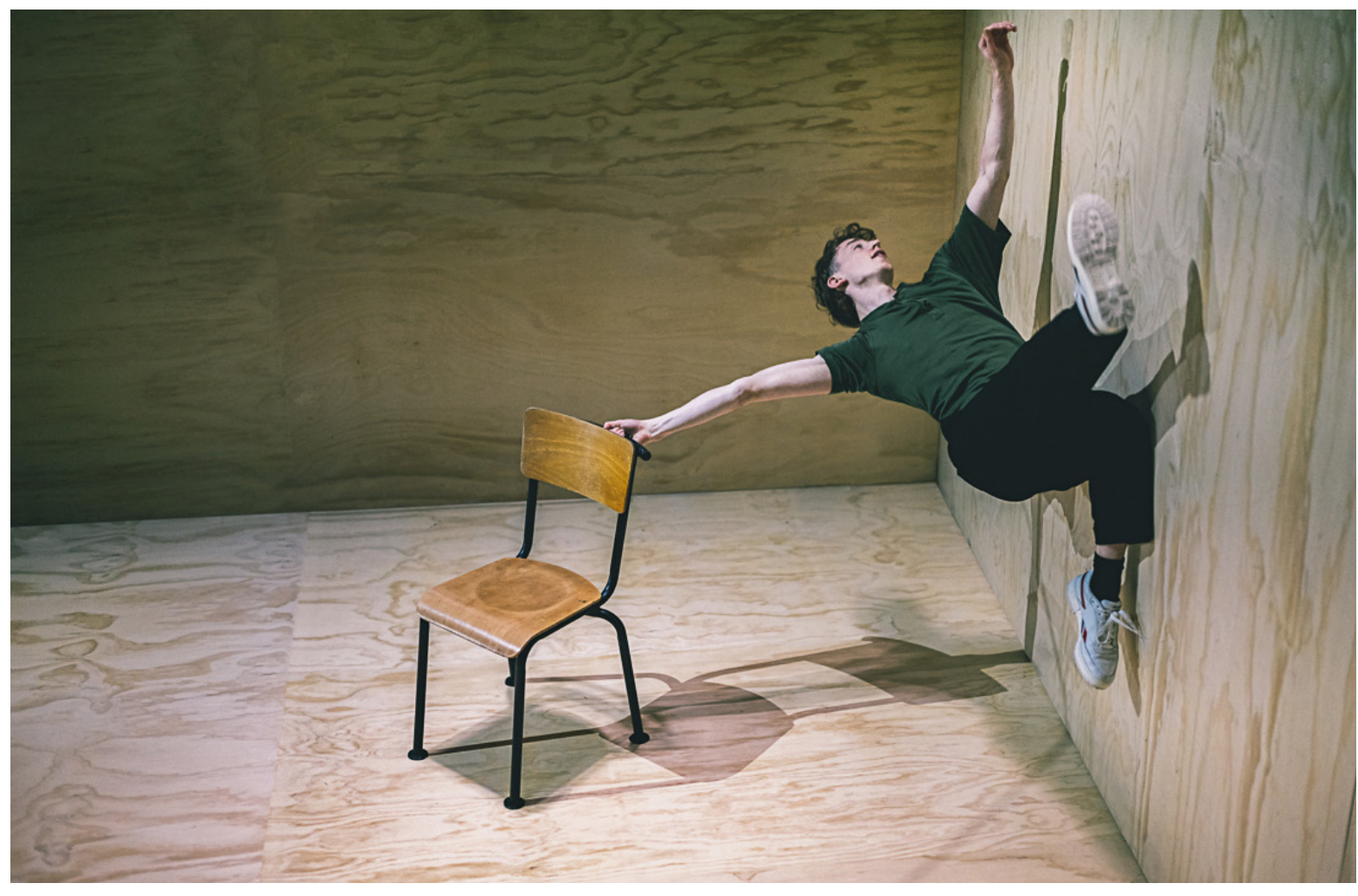

Imagen 4.๑ Rahi Rezvani. Nederlands Dans Theatre, Yoann Bourgeois, I wonder where the dreams I don't remember go. Intérprete: Boston Gallacher. Lucent Danstheater, La Haya, Países Bajos, 2020.

I wonder where the dreams I don't remember go desafía constantemente el sentido de realidad y de todo aquello que percibimos cotidianamente. Juega con las infinitas posibilidades que se pueden lograr entre la estructura de madera, las y los intérpretes, además de los objetos, e invita a explorar otras posibilidades no solo de bailar, sino de existir e irrumpir en la cotidianeidad de la vida. ¿Cómo serían nuestras vidas si pudiéramos vivirlas como en nuestros sueños más irreales?

Más allá del virtuosismo y las habilidades técnicas de las y los intérpretes, es una coreografía que se centra en crear imágenes desafiantes de la realidad. Cada uno desarrolla secuencias coreográficas que denotan movimientos precisos con sutiles tintes de suavidad, como si todos los cuerpos estuvieran suspendidos. Es una propuesta coreográfica que, en tiempos de pandemia y encierro, abre las puertas a otro mundo donde los límites del espacio y el tiempo son difusos y frágiles. Sin duda, permanece en el recuerdo y en los sueños como una poesía en movimiento. 


\section{Ficha técnica}

Compañia: Nederlands Dans Theatre.

Fecha y lugar de estreno: Estreno en línea y presencial 3 diciembre 2020 en Lucent Danstheater en La Haya, Países Bajos.

Dramaturgia: Yoann Bourgeois.

Dirección y coreografía: Yoann Bourgeois.

Escenografía: Yoann Bourgeois.

Iluminación: Yoann Bourgeois y Barry van Oosten.

Escenofonia: Max Richter, Written on the sky, The end of all our exploring, The Departure, Path 19 (yet frailest), November Sequence, This bitter earth/ On the nature of daylight.

Vestuario: Yoann Bourgeois y Yolanda Klompstra.

Reparto: Nicole Ward, Paxton Ricketts, Jianhui Wang, Yukino Takaura, Chloé Albaret, Fay van Baar, Donnie Duncan Jr. y Luca Tessarini.

Fecha y lugar de la última temporada: Presencial en Lucent Danstheater en La Haya, Países Bajos del 3- 19 diciembre 2020. En línea el 3, 4 y 5 de diciembre 2020 en el sitio web de la compañía.

\section{Fuente consultada}

Nederlands Dans Theatre. "I wonder where the dreams I don't remember go". Publitas, https://view.publitas.com/nederlands-dans-theater/seizoen-2020-2021-i-wonderwhere-the-dreams-i-dont-remember-go/page/3. Consultado el 5 de diciembre de 2020. 